\title{
Filosofia e Gestão do Conhecimento: um estudo do conhecimento na perspectiva de Nonaka e Takeuchi
}

\author{
LUIZ TATTO \\ Centro Universitário de Maringá / Programa de Pós-Graduação em Gestão do Conhecimento nas Organizações, \\ MARINGÁ - PR, BRASIL \\ REGINALDO A. BORDIN \\ Centro Universitário de Maringá / Programa de Pós-GraduaÇÃo em Gestão do ConheCimento nas OrganizAÇÕes, \\ MARINGÁ - PR, BRASIL
}

\begin{abstract}
Resumo
Este artigo apresenta um estudo sobre a relação entre a filosofia, o conhecimento e a gestão, segundo a concepção de Nonaka e Takeuchi reflete sua relevância para o desenvolvimento do saber pensar e fazer no contexto das organizações. Também estuda as origens históricas da gestão, reconhecendo os pressupostos assumidos pelo conhecimento. O procedimento metodológico partiu da necessidade de examinar os conceitos de conhecimento presentes na filosofia e na gestão do conhecimento, privilegiando os estudos realizados por Nonaka e Takeuchi e identificando suas diferenças e semelhanças. O estudo indicou que a concepção do conhecimento presente na gestão do conhecimento surgiu da filosofia e nas organizações, assumindo um conceito resultante das experiências particulares e das práticas cotidianas nas organizações.
\end{abstract}

Palavras-chave: Filosofia. Conhecimento. Gestão. Interdisciplinaridade.

\section{Philosophy and Knowledge Management: a study of knowledge from the perspective of Nonaka and Takeuchi}

\section{Abstract}

This theoretical paper presents a study on the relation between philosophy, knowledge and management, according to the conception of Nonaka and Takeuchi. It reflects their relevance to the development of learning how to think and to do, in the context of organizations. It also studies the historical origins of Management, recognizing the assumptions made by knowledge. The methodological procedure stemmed from the need to examine the concepts of knowledge present in philosophy and Knowledge Management, focusing on studies by Nonaka and Takeuchi and identifying their differences and similarities. The study indicated that the conception present in Knowledge Management emerged from the Philosophy and in the Organizations, taking a concept resulting from both particular experiences and everyday practices in organizations.

Keywords: Philosophy. Knowledge. Management. Interdisciplinarity.

\section{Filosofía y Gestión del Conocimiento: un estudio del Conocimiento en la perspectiva de Nonaka y Takeuchi}

\section{Resumen}

Este artículo presenta un estudio sobre la relación entre la filosofía, el conocimiento y la gestión, según la concepción de Nonaka y Takeuchi. Refleja su relevancia para el desarrollo del saber pensar y hacer en el contexto de las organizaciones. También estudia los orígenes históricos de la gestión, reconociendo las suposiciones hechas por el conocimiento. El procedimiento metodológico parte de la necesidad de examinar los conceptos de conocimiento presentes en la filosofía y en la gestión del conocimiento, destacando los estudios desarrollados por Nonaka y Takeuchi y identificando sus diferencias y similitudes. El estudio mostró que el concepto de conocimiento presente en la gestión de conocimiento surge de la filosofía y en las organizaciones toma un concepto que resulta de las experiencias particulares y de las prácticas cotidianas de las mismas.

Palabras-clave: Filosofía. Conocimiento. Gestión. Interdisciplinariedad. 


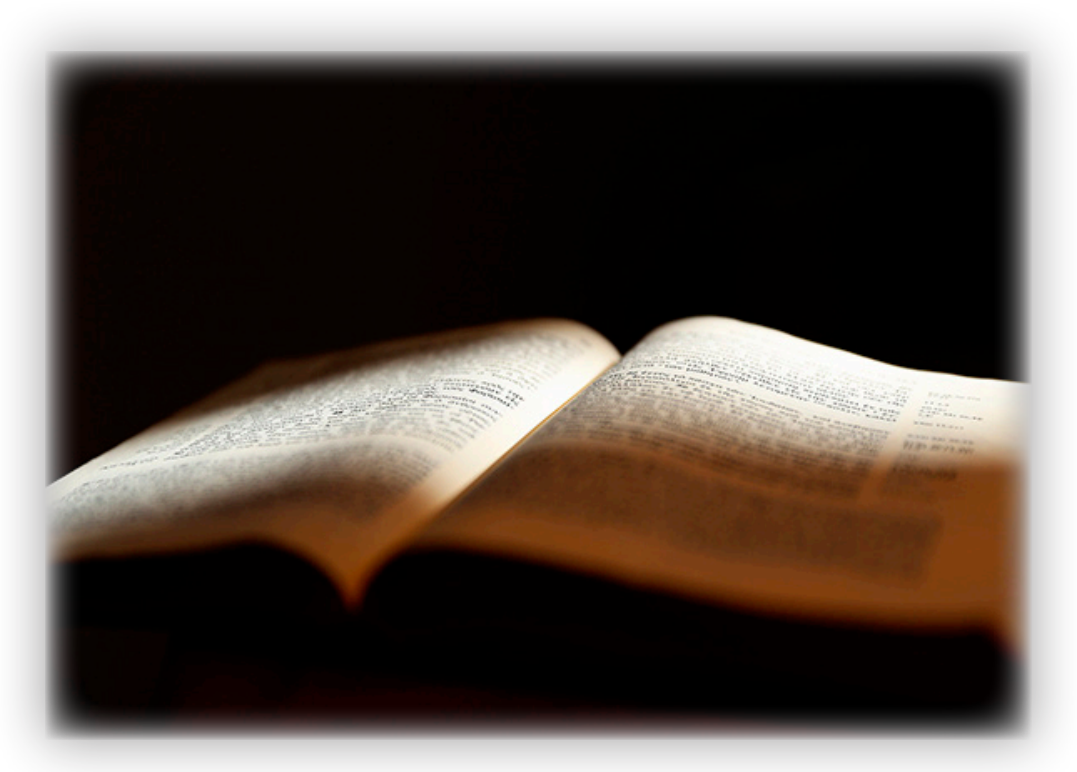

\section{INTRODUÇÃO}

Estudiosos (BARROS e LEHFELD, 1986; CERVO e BERVIAN, 1996; LAKATOS e MARCONI, 2011; QUINN, ANDERSON e FINKELSTEIN, 1996) da metodologia científica, herdeira dos problemas atuais da teoria do conhecimento, dividem em quatro níveis distintos o conhecimento: conhecimento popular, ${ }^{1}$ conhecimento teológico, ${ }^{2}$ conhecimento filosófico ${ }^{3}$ e científico. ${ }^{4}$ Por outro lado, o conhecimento organizacional é o modelo adotado por Nonaka e Takeuchi, entre outros, tais como Barclay e Murray (1997), Leornard-Barton (1995), Sveiby (1998), Von Krogh, Ichijo e Nonaka (2001), Wiig (1993), na perspectiva teórica da gestão do conhecimento. Intentaremos, aqui, resgatar, a partir do conhecimento filosófico, a identificação e explicação do conhecimento e sua gestão no contexto das organizações. As teorias organizacionais e administrativas - tomadas como instrumento de operacionalização do capitalismo e a sua forma - também demonstram uma preocupação com o conhecimento, e, a partir do final do século XX, também com as questões que circunscrevem sua gestão e interdisciplinaridade.

A importância dada no presente ao tema conhecimento em geral e nas organizações deve-se a um complexo conjunto de fatores que apontam para a necessidade de se estudar especificamente esse recurso, dentro do contexto organizacional contemporâneo. Assim, pergunta-se: Como as organizações aprendem? Como se dá a criação do conhecimento? Como avaliar o capital intelectual? Esses questionamentos levam à origem do termo gestão do conhecimento e das contribuições teóricas de Nonaka e Takeuchi (1997; 2008), que se privilegiou neste estudo. Ao considerar esses aspectos, este texto tem por objetivo discutir pressupostos filosóficos utilizados pela gestão do conhecimento, nos referidos autores, que enfatizaram o conhecimento como objeto principal das organizações. Esses autores situaram as mudanças das organizações e compreenderam que, no período que chamaram de era da informação, o conhecimento assumiu um novo papel, que não é aquele elaborado pela tradição filosófica ocidental.

\footnotetext{
* Fonte da imagem: Disponível em <http://davesfreephotos.com/photo/3536/imagebase27-36.html > Acesso em 14 mar. 2016.

${ }^{1}$ Também denominado conhecimento vulgar, conhecimento sensível (senso comum), ou ainda empírico, provém da experiência do dia a dia, fruto do acaso, obtido através de investigações pessoais feitas ao sabor das circunstâncias da vida ou então sorvido do saber dos outros e das tradições da coletividade ou, ainda, tirado da doutrina de uma religião positiva (CERVO, 1996).

${ }^{2}$ Conhecimento revelado, aceito pela fé teológica, relativo a Deus, ser independente e origem do universo, revelado ao homem nas coisas, e no próprio homem, devido à sua imagem e semelhança com o criador. Esse conhecimento é apoiado em doutrinas de proposiç̃̃es sagradas e direcionado à compreensão do mundo em sua totalidade. Sua fonte são os livros sagrados, não somente os cristãos, aceitos racionalmente pelo homem, após apreciação crítica pela história. Caracteriza-se por ser valorativo, inspiracional, sistemático, não verificável, falível e aproximadamente exato (LAKATOS e MARCONI, 2011).

3 "Etimologicamente tem-se como expressão da universalidade do conhecimento humano, de tal forma que a Filosofia é fonte de todas as áreas do conhecimento humano e todas as ciências dela não só dependem como nela se incluem” (BARROS e LEHFELD, 1996, p. 50).

4 "Um conjunto de conhecimentos racionais, certos ou prováveis, obtidos metodicamente, sistematizados e verificáveis, que fazem referência a objetos de uma mesma natureza" (MARCONI e LAKATOS, 2011, p. 22).
} 
O texto propõe-se a refletir sobre o tripé que sustenta a gestão do conhecimento: as linhas teóricas da filosofia, o conhecimento e a própria gestão. Para que possamos compreender o conhecimento e seus desdobramentos como a gestão do conhecimento propõe realizar, o texto destaca as modificações epistemológicas realizadas a partir da construção da administração e das organizações. Nesse cenário, à medida que a produção capitalista se estabelece, com a Revolução Industrial, o conhecimento se transforma em instrumento privilegiado, ajustando-se às necessidades produtivas e se afastando das grandes especulações filosóficas. Assim, o conhecimento assumido pelas organizações, de visão pragmática, passa a ser concebido como fator essencial de competitividade.

\section{A FILOSOFIA, O CONHECIMENTO E A GESTÃO}

Nos últimos anos, especialmente a partir da década de 1990, acentuou-se um debate sobre o conhecimento que não se limitou aos domínios da filosofia, a exemplo da economia e da administração que incorporaram em suas terminologias, conceitos ou categorias até então atribuídos à ciência elaborada pelos gregos. Com o advento da chamada era da informação e do conhecimento, atrelada ao que se denominou terceira Revolução Industrial, estudos foram estimulados sobre o que Capurro (2011) chamou de indústria do conhecimento. Nesse cenário, a questão que se coloca, segundo esse autor, é a de como usarmos o conhecimento e a possibilidade de possuí-lo. Essa perspectiva sugere que a gestão do conhecimento estudou os princípios que orientam as organizações de mercado, com vistas à produção de saberes e, a partir destes, à produção de bens e serviços. Para entender os fundamentos do conhecimento pensados pela gestão do conhecimento, seus principais formuladores dialogaram com os filósofos, a exemplo de Platão, dos empiristas - Bacon e Locke -, Hegel e, mais recentemente, Polanyi (1891-1976), em busca de uma epistemologia.

Teóricos como Nonaka e Takeuchi (1997; 2008), nas obras Criação de conhecimento na empresa e Gestão do conhecimento (Títulos no original The knowledge-creating company, 1995; Hitotsubashi on knowledge management, 2004), alertaram para o fato que a administração, até então, havia ignorado a importância do conhecimento e que era preciso enfrentar o problema a partir de uma nova abordagem. Para isso, procuraram demostrar que havia diferenças entre a tradição ocidental e a oriental. Enquanto a primeira enfatizava a separação entre sujeito e objeto, a segunda destacava o conhecimento como altamente pessoal, oriundo das experiências diretas, as quais não poderiam ser facilmente explicitadas, já que códigos de linguagens não expressariam adequadamente as crenças ${ }^{5}$, intuições e valores subjetivos.

Dessa perspectiva, resulta o pressuposto de que as elaborações teóricas, objetivas, que consideram ser a marca registrada da filosofia ocidental, deveriam ser redefinidas para enfatizar as experiências individuais. Segundo os autores, das experiências compartilhadas no trabalho é que surge o conhecimento. Entendem que compartilhar "o que a empresa representa, que rumo está tomando, em que tipo de mundo quer viver, e como transformar esse mundo em realidade, torna-se muito mais importante do que processar informações objetivas" (NONAKA e TAKEUCHI, 2008, p. 8).

Por isso, nos referidos livros, eles recorreram à tradição filosófica ocidental, na tentativa de pôr em discussão a concepção de conhecimento que consideravam correta, por compreender que conhecimento teria se transformado em um dos fatores fundamentais de competitividade. Essa temática não aparece na filosofia, como veremos adiante, da maneira que Nonaka e Takeuchi compreendem. A justificativa defendida por eles sustenta-se no pressuposto de que as exigências atuais demandam mudanças na forma de pensar sobre o que as organizações lucrativas fazem com o conhecimento. Essa perspectiva sugerida indica que o saber produzido nas e pelas organizações atendem mais às demandas de mercado do que aos interesses defendidos pela tradição filosófica ocidental, que não vinculavam o saber ao lucro. Neste aspecto, em linhas gerais, se pergunta: qual papel cabe à filosofia no processo de conhecimento e sua relação com a GC? Que compreensão Nonaka e Takeuchi têm da filosofia e do conhecimento?

\footnotetext{
${ }^{5} \mathrm{O}$ sentido de crença adotado pelos autores do livro Gestão do conhecimento refere-se a hábitos enraizados pela experiência e que podem ser compartilhados em forma de valores (NONAKA e TAKEUCHI, 2008).
} 
Para entender a natureza do conhecimento, os autores procuraram retomar a produção filosófica atinente à epistemologia, entre elas o racionalismo e o empirismo. ${ }^{6} \mathrm{~A}$ primeira tentativa desse regresso, identificado nas referidas obras de Nonaka e Takeuchi, refere-se ao pensamento de Platão (427a.C.-347a.C.). Identificando-o como racionalista - posição considerada duvidosa - os autores compreenderam que, no filósofo grego, o conhecimento foi definido como "crença verdadeira e justificada". A partir de Platão consideraram, portanto, o conhecimento "um processo dinâmico de justificar a crença pessoal com relação à 'verdade'” (NONAKA e TAKEUCHI, 2008, p. 63).

O sentido que atribuíram a essa concepção parte do pressuposto de que o conhecimento diz respeito a crenças e compromissos estabelecidos e assumidos pelos indivíduos. Segundo Nonaka e Takeuchi, o conhecimento é definido como uma crença verdadeira e justificada porque os sujeitos tendem a justificar constantemente suas crenças sobre o que é verdade contra suas experiências. As crenças, por assim dizer, são aqueles valores ou princípios adquiridos por meio da educação formal e informal, da integração entre os sujeitos nas famílias, nas relações sociais mais amplas, nas tarefas do trabalho e estados emocionais. Ao que parece, os autores sugerem que as crenças podem ser acomodadas quando os indivíduos encontram justificativas que legitimam o comportamento e valores que acreditam ser verdadeiros. Podem ser alteradas quando, na interação social entre as pessoas, que compartilham informações, os indivíduos organizam e reorganizam suas experiências, recebendo ou oferecendo novas perspectivas (NONAKA e TAKEUCHI, 2008).

Assim, o ponto de partida para a produção de conhecimento não é a elaboração de esquemas e modelos teóricos, mas as experiências fomentadas pelas relações travadas no campo prático das organizações. Ainda que partissem de Platão para fundamentar a concepção de conhecimento como crença, essa perspectiva de análise nada tem a ver com a definição platônica. Platão, no Teeteto, afirma que "o saber é opinião verdadeira acompanhada de explicação e que a opinião carente de explicação se encontra à margem do saber" (PLATÃO, (2010, p. 302, 201d)). Em outros termos, a explicação teórica de um fenômeno, que constitui a própria ciência, deve ultrapassar o dado sensível e particular para alcançar as ideias universais, eternas e imutáveis.

A declaração de Platão sugere, a princípio, duas coisas: a primeira é o fato de que a opinião ou crença não pode ser o fundamento do conhecimento, uma vez que é construída a partir dos sentidos, que ele recusa como princípio epistemológico. A segunda diz respeito a um problema mais amplo: uma opinião para constituir-se saber necessita de justificação racional. Todo o conhecimento passa, nessa perspectiva, pelo escrutínio da razão que oferece os critérios e as justificativas de validade do saber. As crenças não podem ser verdadeiras porque carecem de justificativas e provas válidas, ao passo que o saber é conhecimento porque se identifica com a verdade.

As referências de Nonaka e Takeuchi $(1997 ; 2008)$ a respeito da concepção do conhecimento como crença verdadeira e justificada não têm o propósito de discutir a epistemologia platônica, mas identificar as diferenças que eles atribuem entre a clássica tradição filosófica ocidental e a oriental. Nessa perspectiva, para afirmar a concepção de conhecimento como unidade básica que explica o sucesso de uma organização, os autores japoneses entendem que no Ocidente prevalece uma visão dualista. O conhecimento, segundo eles, deriva da separação do sujeito e do objeto percebido, e os indivíduos adquirem conhecimento pela análise dos objetos externos. A rigor, entendem que a epistemologia moderna enfatiza o conhecimento teórico em detrimento do prático.

Para sustentar essa posição recorreram ao pensador moderno René Descartes (1596-1650), a quem atribuíram o pressuposto de que "[...] o conhecimento verdadeiro pode ser obtido apenas pela mente, não pelo corpo" (NONAKA e TAKEUCHI, 2008, p. 25). Os autores japoneses entenderam que em Descartes mente e corpo, por serem distintos, não têm as mesmas atribuições, e, por isso, as condições de possibilidade do conhecimento estariam na mente e não no corpo. Ainda que essa discussão seja mais abrangente do que Nonaka e Takeuchi supõem, o tratamento dessa questão abrange duas consequências para esses autores. A primeira refere-se à tentativa deles superarem o que entendiam por dualismo ocidental, buscando uma concepção de conhecimento mais unitária. Na segunda, os autores japoneses objetaram o filósofo moderno, argumentando que nas organizações a ênfase do conhecimento reside mais na experiência corporal do que no intelectual, razão pela qual eles preferem dialogar com os empiristas, a exemplo de Locke (1632-1704).

\footnotetext{
${ }^{6}$ Por racionalismo entende-se aquela atitude de quem confia nos procedimentos da razão para a determinação de crenças ou de técnicas em determinado campo. Empirismo é uma corrente filosófica que estabelece a experiência como critério ou norma da verdade. Nega-se o caráter absoluto da verdade e compreende-se que a verdade deve ser posta à prova, modificada, corrigida ou abandonada (ABBAGNANO, 2007).
} 
Nonaka e Takeuchi não aprofundam a perspectiva do conhecimento em John Locke, precursor do empirismo inglês. Limitam-se a mencionar que o autor do livro Ensaios sobre o entendimento humano, de 1690, não considerou as ideias inatas de Descartes e que o inglês colocou na experiência a base fundamental do conhecimento. Ao que tudo indica, o propósito foi demonstrar a oposição estabelecida entre Descartes e Locke, para destacar a dualidade que a filosofia moderna havia alcançado. Embora não deixem explícita a preferência pelas proposições do empirismo inglês, é possível constatar a defesa que Nonaka e Takeuchi fazem da experiência como base do conhecimento. Esse ponto de vista apoia-se na hipótese de que eles buscam enfatizar que o conhecimento é resultante da interação de um sujeito com o outro e nas trocas que realizam no cotidiano. É na socialização, portanto, que ocorre o compartilhamento das experiências e, por extensão, da produção do conhecimento. Além disso, o que confirma nossa hipótese, Nonaka e Takeuchi afirmam que "os aprendizes trabalham com seus mestres e aprendem sua arte não através da linguagem, mas sim através da observação, da imitação e da prática” (NONAKA e TAKEUCHI, 1997, p. 69).

O princípio esboçado pelos referidos autores a respeito do conhecimento parte do pressuposto de que ele é construído mediante experiências pessoais, que podem ser imitadas e realizadas por outros sem, como dizem, a linguagem. Nesse aspecto, o que sugerem é o fato de que, ao partir das crenças como horizonte de ação, privilegiam as interações ocorridas no cotidiano de uma organização, independentemente de especulações teóricas. $O$ fato de considerarem que a linguagem não é o "veículo" do conhecimento sugere que a ciência, com seus atributos teóricos, tende a legitimar aquilo que a experiência determina e requisita. Soluciona, portanto, problemas de ordem prática dentro de uma organização, com fins utilitários.

Um exemplo que pode caracterizar essa ideia é o diálogo que Nonaka e Takeuchi realizaram com concepções filosóficas que enfatizam categorias como a dialética e a contradição, a exemplo de Hegel (1774-1831) e mesmo de Marx (1818-1883). Ao compreenderem que a realidade está em contínua mudança e que as organizações, na chamada "Sociedade do Conhecimento", devem estar atentas a novos rearranjos, os autores da Gestão do conhecimento entenderam que "a chave para liderar o processo de criação do conhecimento é o raciocínio dialético" (NONAKA e TAKEUCHI, 2008, p. 21). Mas o que entendem por dialética e contradição?

O pressuposto de que partem para resolver esse problema reside na afirmação de que a realidade é mutável e, por isso, não há um princípio que seja estável. Assim, para definir dialética, recorreram a duas características. A primeira é a ênfase na mudança e a segunda é a ênfase nos opostos. De acordo com as afirmações de Nonaka e Takeuchi (2008), a mudança ocorre por meio do conflito e da oposição entre aspectos diferentes que, em movimento, um nega o outro para possibilitar um terceiro pressuposto. Ao tentar reproduzir a dialética hegeliana, afirmando que uma tese mostra-se inadequada quando negada por uma antítese, eles deslocaram os pressupostos dialéticos hegelianos, que objetivam conhecer uma verdade histórica e universal, meta da razão, para a ambiência da gerência das organizações.

A concepção, que nada tem a ver com a dialética de Hegel, apresentada por Nonaka e Takeuchi (2008) foi adaptada nos limites das opções e decisões mercadológicas de uma organização. Assim, a síntese (o interesse no cliente) é o resultado da interação entre a percepção interna (tese) de uma organização sobre os interesses manifestos pelos sujeitos e a percepção externa (antítese). Desse modo, as experiências acumuladas servem como referência - não como norma estática - para atender a demandas originadas nos setores produtivos e que dependem de interações entre os membros envolvidos para alcançar soluções comuns. As saídas dos problemas que surgem passam a se inserir na percepção das mudanças estabelecidas no cenário competitivo. Portanto, a dialética implica a compreensão das alterações que ocorrem por conta das oposições e divergências e, por isso, as experiências anteriores são superadas em nome do que denominaram de rotina criativa.

Circunscritas no cenário da competição, as oposições foram definidas por Nonaka e Takeuchi como pressupostos que se contrastam, tais como: caos e ordem, mente e corpo, parte e todo, dedução e indução, burocracia e força de trabalho, entre outros. Ainda que estejam apresentados em polos diferentes, Nonaka e Takeuchi sugerem que eles fazem parte do mesmo movimento. São interdependentes: um se define a partir do outro tanto quando neles há elementos de seu contrário. Essa mesma perspectiva pode ser aplicada ao conceito de contradição, no sentido de que ela motiva uma organização a aceitar o diferente, a fim de pensá-lo e produzir novos conhecimentos e, em decorrência, produtos (NONAKA e TAKEUCHI, 2008).

Se compararmos a concepção que elaboraram sobre a dialética e contradição com a de Hegel, cumpre fazer algumas observações. No caso de Nonaka e Takeuchi, as contradições não operam na ambiência do pensamento racional, que possibilitaria alcançar a verdade. Ocorre, apenas, na superação de uma ação particular para o estabelecimento de outra. Quer dizer, ocorre quando uma ideia ou decisão, que corresponde a um produto, é superada por outra, que resulta em outro produto, 
considerado inovador. Distintamente, em Hegel "constitui um lado capital da lógica a intelecção de que a natureza do pensar mesmo é a dialética, de que o pensar enquanto entendimento deve necessariamente cair no negativo de si mesmo - na contradição" (HEGEL, 1995, p. 51, §11). A visão de que a natureza do pensar consiste precisamente na dialética, enquanto entendimento, vem a dar no negativo de si mesmo, na contradição, constitui um aspecto capital da lógica.

Em Hegel, portanto, a dialética corresponde à natureza do próprio pensamento racional, que busca, por meio de categorias, apreender a totalidade de um fenômeno. A contradição por Hegel aludida é um aspecto importante, diferente da pretendida por Nonaka e Takeuchi, porque incorpora princípios e formas que são superados e negados, para apontar outros, em um movimento que leva à verdade da totalidade. Nesse processo, a racionalidade traz à luz o que está escondido e articula as partes que se apresentam separadas. Dessa maneira, o pensamento dialético de Hegel não corresponde ao que foi apresentado por Nonaka e Takeuchi, pois estes autores pretendem justificar a transformação do conhecimento subjetivo (tácito) em explícito (um conhecimento pressupostamente teórico), tal qual eles entenderam a partir de Michel Polanyi (NONAKA e TAKEUCHI, 2008).

Na busca por uma teoria do conhecimento, que tendesse superar o que consideravam ser visão dualista da filosofia ocidental, Nonaka e Takeuchi manifestaram interesse pelo modelo de Polanyi, que levou em conta dois aspectos: o conhecimento tácito e o explícito. Nos referidos autores orientais, o conhecimento tácito foi definido como altamente pessoal, "enraizado nas ações e na experiência corporal do indivíduo, assim como nos ideais, valores ou emoções que ele incorpora" (NONAKA e TAKEUCHI, 2008, p. 19). Esse tipo de conhecimento, de característica indutiva e circunstancial, pode ser compreendido a partir da ênfase cotidiana no conhecimento, no sentido de resultar de experiências individuais e da visão pessoal de mundo. Por isso, os palpites e intuições decorrem dele tanto quanto as habilidades de um artesão, adquiridas por anos de aperfeiçoamento.

Por outro lado, o conhecimento denominado explícito foi definido como formal, sistemático e objetivo. Ele se caracteriza por ser expresso em palavras, números ou sons e compartilhado na forma de dados, fórmulas científicas e recursos visuais, entre outras formas (NONAKA e TAKEUCHI, 2008). Entre os aspectos que o definem, está o fato dele ser codificado pela linguagem e transmitido por ela. Assim, predomina a natureza teórica e formal do conhecimento, em contraposição ao tácito, que é prático. Ainda que sejam diferentes, Nonaka e Takeuchi entendem que deve haver interação entre um e outro. O conhecimento tácito precisa ser convertido em explícito para que seja validado e transformado em novos inventos ou produtos, como pretendem as organizações.

Dessa maneira, na abordagem realizada por Nonaka e Takeuchi (1997) tais conhecimentos representam o aspecto mais importante de uma organização porque permitem combinar e converter experiências em conhecimentos. Essa abordagem epistemológica ambiciona referendar o pressuposto de que o conhecimento é o elemento essencial para a competição. A finalidade primeira, destacada pelos autores, não é alcançar as verdades universais que a filosofia ocidental, pelo menos até meados do século XIX, desejava. O pressuposto primordial é a transformação do conhecimento como fonte de vantagem competitiva, portanto, como produto.

Desse princípio, resulta algumas consequências tidas como elementares para as organizações atuais, as quais perceberam a importância do conhecimento e, por isso, investiram na gestão do conhecimento. A primeira refere-se à redução do conhecimento à esfera prática e utilitária porque os resultados requeridos pelos saberes devem possibilitar inovação contínua e, por meio dela, vantagem na competição. As habilidades requeridas não são as mesmas ordenadas pela filosofia e as epistemologias que as fundamentam. A segunda implica o fato de que os autores, ao partirem de uma concepção mutável de mundo, entendem que não pode haver um conhecimento universalmente válido. Se a realidade muda, não haveria um conhecimento estável, já que os mesmos princípios não se aplicariam para outra circunstância.

Assim, Nonaka e Takeuchi $(1997 ; 2008)$ dialogaram com a filosofia e com outras áreas do conhecimento para articularem os princípios da gestão do conhecimento. Ao retomar o pensamento filosófico, vislumbraram nele a possiblidade de explicar e descrever as formas de como ocorre o conhecimento e como ele se relaciona com as teorias organizacionais. Essas perspectivas epistemológicas anunciadas na filosofia, na economia e na sociologia - a exemplo de Auguste Comte, que privilegiou a observação dos fatos em detrimento do conhecimento teológico e metafisico - podem ser reconhecidas na gestão do conhecimento, que parte de estudos de caso para construir modelos de conhecimento, como veremos em suas origens. Esse aspecto, por fim, pode ser compreendido quando se leva em consideração as abordagens contemporâneas realizadas pela gestão que repensou os modos da produção e do trabalho e, por extensão, o papel do conhecimento. 


\section{A GESTÃO E SEUS FUNDAMENTOS}

Gestão ou administração é uma disciplina que, ao mesmo tempo, apresenta uma visão paradoxal. É considerada um campo de conhecimento com características de senso comum e complexa. Disciplina relativamente fácil de ser ensinada comparativamente a outros cursos, entre os quais a engenharia, a física ou a medicina. Naturalmente, isso é uma provocação. A sua prática e bons resultados envolvem um componente de ciência, de arte e de prática. Em outras palavras, envolve uma grande dose de habilidades sociais, experiência e intuição. Como também um conjunto de pressupostos, modelos mentais que moldam decisões, ações e comportamentos.

A gestão, batizada no Brasil, de administração, na formação do capitalismo, utiliza dos conhecimentos produzidos nos campos da matemática, biologia, sociologia, psicologia, direito, economia, contabilidade, ciência política, geografia e estatística, acrescentados das contribuições que resultaram na operacionalização da Revolução Industrial, principalmente, por Taylor, Fayol, Ford e Mayo. Portanto, as origens do capitalismo e dos elementos mais próximos da gestão moderna estão ancoradas nesse processo. Os desafios, entre outros, que antecederam a Revolução Industrial era pensar, desenvolver e construir formas para que trabalhadores manuais e artesãos em um ambiente de trabalho pudessem implantar a divisão e o controle de operações, além de orientar a produção de acordo com as necessidades do mercado. De algum modo, esse era o cenário pensado pelo escocês Adam Smith (1723-1790), na sua obra A riqueza das nações (1776). Porém, isso já havia sido definido em A república, de Platão, como o simples processo pelo qual o trabalho é alocado na atividade em que é mais produtivo. Adam Smith resgata esse conceito de Platão e incorpora na ênfase da divisão do trabalho a possibilidade para a produção de riqueza.

A divisão social do trabalho alcançou um novo patamar com a Revolução Industrial, que tem como berço, a Inglaterra. Em suas origens, duas etapas que caracterizam os avanços das estruturas produtivas, podem, inicialmente, ser identificadas. A primeira fase vai de 1780 a 1850 (revolução do carvão, do ferro e das ferrovias) e, a segunda fase vai de 1850 a 1914 (revolução do aço e eletricidade), que em épocas e ritmos diferentes espalha-se pela França, Alemanha, Bélgica e Itália. A Revolução Industrial caracteriza-se pela modificação do trabalho, na sua divisão, na concentração de trabalhadores e na materialização do trabalho assalariado. Passa-se a substituir a força motriz humana pela máquina. Entre os fatores que tornaram isso possível estava o progresso técnico-científico e as grandes invenções e descobertas aplicadas às indústrias têxteis, às metalúrgicas e aos sistemas de transportes (ferroviários e marítimos). Acrescenta-se a mentalidade burguesa de setores da agricultura que, em sintonia com as atividades urbanas, redirecionavam sua produção, oferecendo matéria-prima, como foi o caso da indústria algodoeira, que havia se desenvolvido como um subproduto do comércio ultramarino (HOBSBAWM, 2002).

Na transição do século XIX para o século XX, a produção industrial passa a ser racionalizada no sentido de alinhar o processo produtivo para torná-lo cada vez eficiente. Frederick Wislow Taylor é figura pioneira na construção desse processo. O livro "The principles of scientific management", publicado em 1911, é ícone do desafio enfrentado em organizar o trabalho industrial com ênfase nas experiências realizadas no nível de produção, "chão de fábrica", bottom-up. Entretanto, Taylor avaliava que apenas as experiências e as observações efetivadas pelos operários não assegurariam o rendimento esperado de uma organização. Mais que isso: era preciso que, para ampliar os resultados do trabalho, uma "pessoa competente", de fora do processo, estudasse o uso do tempo e do ritmo do trabalho. Para isso, propôs métodos e instrumentos melhores, entre os quais aqueles que pertenciam ao que considerava ser uma análise científica do uso do tempo. Assim, planejamento e gerenciamento do trabalho passariam, de acordo com Taylor, a depender de que quase todos os atos dos trabalhadores fossem "precedidos de atividades preparatórias da direção, que habilitam os operários a fazerem seu trabalho mais rápido e melhor do que em qualquer outro ramo" (TAYLOR, 1995, p. 34).

Por outro lado, na obra Administração industrial geral (Administration industrielle et generale), publicada em 1916, Henri Fayol (1841-1925), enfatizou o princípio do planejamento, que pode ser entendido como: planejar, organizar, controlar, coordenar e comandar, top-down. Tais características sugerem que Fayol ocupou-se com as funções da administração, cujas atribuições recaíam sobre o que chamava de "agentes superiores das grandes empresas" (FAYOL, 1989, p. 37). Dessa maneira, considerava que não bastavam conhecimentos puramente técnicos para o bom desempenho administrativo, mas, sobretudo, os chefes ou diretores deveriam aplicar-se aos assuntos mais abrangentes, o que requisitava uma educação mais aprimorada.

Com esse ponto de vista, Fayol via como um equívoco o fato de um chefe ser escolhido por seus atributos técnicos. Para ele, um administrador deveria ter outros valores, entre os quais, as "qualidades de presença, autoridade, ordem, organização e 
outras, que são os próprios elementos da capacidade administrativa" (FAYOL, 1989, p. 37). Em síntese, enfatizou que os agentes administrativos deveriam aprimorar certas habilidades e conhecimentos que os capacitassem a tomar decisões esclarecidas sobre todas as coisas, tais como: inteligência e vigor intelectual, qualidades morais (como o sentimento de dever), sólida cultura geral e capacidade administrativa (entre as quais, previsão, organização, comando, coordenação e controle) (FAYOL, 1989).

Nas origens da Gestão e do alinhamento da produção industrial, outro personagem se destacou, além de Taylor e Fayol. Henry Ford (1863-1947), como empresário da indústria automobilística, aliou o "bottom-up" de Taylor ao "top-down" de Fayol, para dar visibilidade e popularidade ao automóvel. É atribuído a ele o "fordismo", isto é, a produção em série de grande quantidade de automóveis a baixo custo recorrendo ao artifício conhecido como "linha de montagem". Esse sistema, que funcionava pelo uso de esteiras, tinha condições de fabricar um carro a cada 98 minutos, além dos altos salários oferecidos a seus operários. Uma verdadeira "lua-de-mel" entre capital e trabalho. O legado de Henry Ford modificou todo o pensamento da época. Foi através dele que se desenvolveu a mecanização do trabalho, produção em massa, padronização do maquinário e do equipamento e, por consequência dos produtos, forte separação do trabalho manual em relação ao intelectual.

Para Ford, o operário não precisava pensar apenas como fazer seu trabalho, mas efetuá-lo com o mínimo de movimentação possível. Também colocou em prática a política de metas, afirmando que $\mathrm{X}$ carros deveriam ser produzidos em $\mathrm{Y}$ dias. Além disso, revolucionou o tratamento dispensando aos trabalhadores, pois melhorou o salário deles. Ao mesmo tempo em que se tinha o pagamento de um salário substancial para aqueles que trabalhavam com a produção e a distribuição, ocorria o aumento de poder de compra proporcionalmente, criando um movimento econômico cíclico e virtuoso. Por esses motivos, também Henry Ford apresenta-se como marco, nos estudos da gestão. Nesse cenário, somado a outros fatores, emerge um impetuoso desenvolvimento da civilização industrializada, ancorada principalmente na tecnologia e seus problemas.

Os últimos foram retratados jocosa e criticamente por Charles Chaplin em "Modern Times" (título no Brasil e em Portugal, "Tempos Modernos"). Um clássico filme americano de 1936, do cineasta Charles Chaplin, em que seu famoso personagem "O vagabundo" (The tramp) tenta sobreviver em meio ao mundo moderno e industrializado. No filme, emerge uma forte crítica ao capitalismo, anglicanismo, militarismo, liberalismo, conservadorismo, stalinismo, satanismo, cristianismo, fascismo, nazismo, fordismo e imperialismo, juntamente com uma crítica aos maus tratos que os empregados passaram a receber depois da Revolução Industrial. Além do cinema, manifestações contrárias, notadamente no campo da filosofia, passam a ter uma visão pessimista em relação à sociedade industrial, ao contexto da racionalidade tecnológica. Desconfia-se do avanço científico por acreditar que ele não resolveu os complexos problemas humanos, expostos pela crise de 1929 e pelas duas guerras mundiais (1914 a 1918 e 1939 a 1945).

Um exemplo do pessimismo referente aos avanços da técnica pode ser visto em Herbert Marcuse (1898-1979), que apontou o caráter contraditório da técnica. Ela, por si só, pode promover tanto o autoritarismo quanto a liberdade, tanto a escassez quanto a abundância, tanto o aumento quanto a abolição do trabalho árduo. Para demarcar essa contradição, Marcuse afirmou que, na Alemanha dos anos 1940, com o partido nazista, a economia operou de maneira altamente racionalizada e mecanizada, com a máxima eficiência na produção e que também atuou no interesse da opressão totalitária e da escassez continuada. O que chamava de tecnocracia implicava, nos regimes totalitários (fascismo, nazismo e stalinismo), um reino de terror sustentado não somente pela força bruta, mas também pela manipulação do poder inerente à tecnologia: a intensificação do trabalho, a propaganda, o treinamento de jovens e a organização da burocracia governamental, industrial e partidária seguiam diretrizes de maior eficiência tecnológica (MARCUSE, 1999).

Como tentativa de resposta à crise instalada, Mayo (1933), na época, passa a estudar as consequências e problemas da sociedade industrializada, tornando-se conhecido pela Experiência de Hawthorne, na qual, entre outras indicações, afirma que a colaboração na sociedade industrializada não pode ser entregue ao acaso, enquanto se cuida apenas dos aspectos materiais e tecnológicos do progresso humano. A psicologia, a partir de então, passa também a estar a serviço do progresso material e tecnológico na medida em que estuda os fatores humanos que compõem o contexto produtivo. Acrescenta-se a isso, as linhas da psicologia preocupadas em refletir aspectos voltados para as necessidades humanas, a exemplo das contribuições de Maslow (1908-1970). Entre elas, podemos apontar a pirâmide das necessidades que compreende a natureza humana a partir das necessidades fisiológicas para as de autorrealização.

O que se pode compreender é que no desenvolvimento do capitalismo no século XX e início do XXI, o conhecimento significava resposta às crises de natureza econômica, mercadológica e social. No contexto de instabilidade e complexidade que 
caracterizam a contemporaneidade, novos desafios se apresentam e o conhecimento passou a ser o ponto de referência, em resposta às novas demandas. Assim, tanto a filosofia quanto a gestão procuram sinalizar possíveis respostas, que se apresentam de maneiras diferentes como a pretendida pelas organizações.

\section{O CONHECIMENTO DAS E NAS ORGANIZAÇÕES}

Hoje o principal recurso para os indivíduos e para a economia em geral é o conhecimento, principalmente, aquele requisitado pelas organizações. Terra, mão de obra e capital - os tradicionais fatores de produção circunscritos pelos economistas - tornam-se secundários, mas não desaparecem. Com facilidade, podem ser obtidos, desde que haja conhecimento especializado. Toffler argumenta ser o conhecimento um recurso relevante para a economia. Além disso, segundo ele, "todos os sistemas econômicos estão instalados sobre uma 'base de conhecimento. Todas as empresas dependem da preexistência deste recurso socialmente constituído. [...] esse recurso - em parte pago, em parte explorado gratuitamente - é, agora, o mais importante de todos" (TOFFLER, 1995, p. 108). O conhecimento especializado por si só não produz nada. Torna-se produtivo somente quando está integrado a uma tarefa. Por isso que a sociedade do conhecimento também é uma sociedade de organizações: cada organização, empresarial ou não, tem como finalidade e função a integração de conhecimentos especializados numa tarefa comum. Significa dizer, por outro lado, que cada organização tem de se preparar para o abandono de tudo aquilo que faz. Gerentes devem aprender a fazer, a cada dois ou três anos, a seguinte pergunta sobre cada processo, produto, procedimento e política: "Se já não fizéssemos isto, será que começaríamos a fazer agora, sabendo aquilo que sabemos?" Se a resposta for não, a organização deverá perguntar: “Então o que faremos agora?” E ela tem de fazer algo, e não dizer: “Vamos fazer outro estudo". Cada vez mais as organizações terão de planejar o abandono, ao invés de tentar prolongar a vida de um produto. Assim, por quase meio século, Drucker $(1994,1998)$ tem inspirado e educado gerentes com seus marcantes artigos, desde estratégia corporativa e estilos gerenciais até mudanças sociais e conhecimento.

Drucker (1998) enfatiza que o conhecimento torna os recursos móveis. Ao contrário dos trabalhadores manuais, os "trabaIhadores do conhecimento" possuem os meios de produção. Carregam o conhecimento em suas cabeças, podendo levá-lo consigo. Essas pessoas, em decorrência disso, não podem ser "gerenciadas" no sentido comum da palavra. Elas nem mesmo serão funcionárias das organizações (em muitos casos), mas empreendedoras, peritas, parceiras de empreendimentos, consultoras, trabalhadoras em tempo parcial, entre outras. Ademais, um número crescente dessas pessoas irá se identificar não pela organização que as paga, mas por seu próprio conhecimento.

Segundo esse autor, o centro de uma sociedade, de uma economia e de uma comunidade moderna não é a tecnologia, não é a informação, não é a produtividade; talvez, nem seja o conhecimento. O centro da sociedade moderna é a instituição administrada. Hoje, a instituição administrada é a maneira usada pela sociedade para conseguir que as coisas sejam feitas. $\mathrm{E}$ a administração é a ferramenta específica, a função específica, o instrumento específico para tornar as instituições capazes de gerar resultados (DRUCKER, 2014).

Em resumo, as instituições hoje se apresentam como espaço privilegiado para prover, desenvolver e assimilar conhecimentos. Essa característica marca um novo cenário distinto dos anteriores. Tanto Nonaka e Takeuchi quanto os teóricos da administração e da gestão, a exemplo de Fayol, Toffler e Drucker, enfatizaram o conhecimento como uma das principais características contemporâneas, o que sugere a necessidade de um pensar multidisciplinar e transdisciplinar como recurso para enfrentar a complexidade atual. 


\section{CONCLUSÃo}

Neste artigo, procurou-se responder aos problemas referentes ao conhecimento e às suas relações com a filosofia e a gestão do conhecimento. Ao refletir a partir dos pressupostos filosóficos, foi possível identificar diferenças na construção do conhecimento, segundo a perspectiva teórica de Nonaka e Takeuchi. O que a filosofia apresenta é o conhecimento como objeto de especulação, com vistas à busca da verdade. Em contrapartida, na gestão, o conhecimento tem outra perspectiva; qual seja, a concepção, desenho, elaboração e venda de um produto ou serviço.

O que se compreende é que, historicamente, as transformações da produção, do trabalho e do consumo, colocaram novos problemas. Em resposta a eles, Taylor, Fayol, Peter Drucker e mais recentemente, Nonaka e Takeuchi, a seu modo e tempo, apontaram respostas aos desafios, considerando os aspectos práticos e organizacionais necessários ao desenvolvimento do capitalismo. De outro modo, a filosofia oferece, além da crítica, os instrumentos teóricos para pensar o conhecimento e sua aplicação.

Por sua vez, a gestão do conhecimento, na sua origem e construção, dialogou com a filosofia, na tentativa de buscar fundamentos que de algum modo a legitimem. Por exemplo, o entendimento que Nonaka e Takeuchi tiveram sobre o conhecimento como crença justificada e verdadeira remonta a Platão. Outro aspecto é o empirismo presente na filosofia como fundamento do conhecimento, resultante das experiências particulares, que, na gestão, se remete às práticas cotidianas das organizações.

É importante considerar que, na emergência do que se chamou sociedade do conhecimento, a gestão ainda é um campo em construção, tanto do ponto de vista teórico quanto dos seus resultados nas organizações. O que se sugere a partir dessas reflexões é a necessidade de trabalhos ou estudos focados no conhecimento, em suas diversas matizes, seja no geral como no contexto das organizações. Outra vertente é realizar estudos a partir de casos para conhecer o estado da arte da gestão do conhecimento, a fim de identificar seus pressupostos e possíveis tendências. 


\section{REFERÊNCIAS}

ABBAGNANO, N. Dicionário de filosofia. 2. ed. São Paulo: Martins Fontes, 2007.

BARCLAY, R. U.; MURRAY, P. What is knowledge management. In: BARCLAY, R. U.; MURRAY, P. A knowledge praxis. [S.I.]: [s.n.], 1997.

BARROS, A. J. P. de; LEHFELD, N. A. de S. Fundamentos de metodologia. São Paulo: McGraw-Hill, 1996.

CAPURRO, R. Gestão do conhecimento cético. Perspectivas em Gestão \& Conhecimento, João Pessoa, v. 1, n. 1 p. 4-14, jan./jun. 2011.

CERVO, A. L.; BERVIAN, P. A. Metodologia científica. 4. ed. São Paulo: Makron, 1996.

DRUCKER, P. A sociedade pós-capitalista. São Paulo: Editora Pioneira, 1994.

DRUCKER, P. A profissão de administrador. São Paulo: Editora Pioneira, 1998.

DRUKER, P. Os novos paradigmas da administração. Disponível em: <http://www.lgti.ufsc.br/O\&m/aulas/Aula1/paradgmas\%20adm. htm>. Acesso em: 1 set. 2014.

FAYOL, H. Administração industrial e geral. 10. ed. São Paulo: Atlas, 1989.

HEGEL, G. W. F. Enciclopédia das ciências filosóficas em compêndio: 1830. São Paulo: Loyola, 1995.

HOBSBAWM, E. A era das revoluções. 16. ed. Rio de Janeiro: Paz e Terra, 2002.

LAKATOS, E. M.; MARCONI, M. de A. Metodologia cientifica. 6. ed. São Paulo: Atlas, 2011.

LEONARD-BARTON, D. Wellsprings of knowledge. Boston: Harvard Business School Press, 1995.
MARCUSE, H. Algumas implicações sociais da tecnologia moderna. In: MARCUSE, H. Tecnologia, guerra e fascismo. São Paulo: Fundação Editora da UNESP, 1999. 71-104 p.

MAYO, E. The human problems of an industrial civilization, Nova York: The Macmillan Co., 1933.

NONAKA, I.; TAKEUCHI, H. Criação do conhecimento na empresa: como as empresas japonesas geram a dinâmica da inovação. Rio de Janeiro: Campus, 1997.

NONAKA, I.; TAKEUCHI, H. Gestão do conhecimento. Porto Alegre: Bookman, 2008.

PLATÃO. Teeteto. 3. ed. Lisboa: Editora Calouste Gulbenkian, 2010.

QUINN, J. B.; ANDERSON, T.; FINKELSTEIN, S. Managing professional intellect: making the most of the best. Harvard Business Review, New York, p. 71-80, mar./apr. 1996.

SVEIBY, K.-E. A nova riqueza das organizações: gerenciando e avaliando patrimônios de conhecimento. Rio de Janeiro: Campus, 1998.

TAYLOR, F. W. Princípios de administração científica. 8. ed. São Paulo: Editora Atlas, 1995.

TOFFLER, A. Powershift - as mudanças do poder. 4. ed. Rio de Janeiro: Record, 1995.

VON KROGH, G.; ICHIJO, K.; NONAKA, I. Facilitando a criação do conhecimento: reinventando a empresa com o poder da inovação contínua. Rio de Janeiro: Campus, 2001.

WIIG, K. M. Knowledge management foundations: thinking about thinking: how people and organizations create, represent, and use knowledge. Arlington, Texas: Schema Press, 1993.

Luiz Tatto

Doutor em Engenharia de Produção pela Universidade Federal de Santa Catarina/UFSC; Professor e pesquisador do Programa de Pós-Graduação em Gestão do Conhecimento nas Organizações da UniCesumar - Centro Universitário de Maringá. E-mail: tattoluiz@gmail.com

Reginaldo A. Bordin

Doutor em Educação pela Universidade Estadual de Maringá/UEM; Professor e pesquisador do Programa de Pós-graduação em Gestão do Conhecimento nas Organizações da UniCesumar-Centro Universitário de Maringá. E-mail: r.a.bordin@uol.com.br 